\title{
Mobile Cloud Computing for Telemedicine Solutions
}

\author{
Mihaela GHEORGHE \\ The Bucharest University of Economic Studies \\ mihaela.gheorghe@ie.ase.ro
}

\begin{abstract}
Mobile Cloud Computing is a significant technology which combines emerging domains such as mobile computing and cloud computing which has conducted to the development of one of the most IT industry challenging and innovative trend. This is still at the early stage of development but its main characteristics, advantages and range of services which are provided by an internet-based cluster system have a strong impact on the process of developing telemedicine solutions for overcoming the wide challenges the medical system is confronting with. Mobile Cloud integrates cloud computing into the mobile environment and has the advantage of overcoming obstacles related to performance (e.g. battery life, storage, and bandwidth), environment (e.g. heterogeneity, scalability, availability) and security (e.g. reliability and privacy) which are commonly present at mobile computing level. In this paper, I will present a comprehensive overview on mobile cloud computing including definitions, services and the use of this technology for developing telemedicine application.
\end{abstract}

Keywords: Telemedicine, Healthcare, Mobile Cloud Computing, Cloud Computing, Service, Smartphone

\section{1} Introduction

Mobile Cloud Computing is one of the emerging technologies which now represent a reality and a low-cost computing power resource which has gained popularity among all business categories, especially medium and small size, governmental or medical organizations, as more people are realizing the power and benefits of cloud environments.

Mobile technology has expanded dramatically in the last decades all around the world. Along with the adoption and development of $3 \mathrm{G}$ and 4G technologies, these advancements have had a huge impact on the growth of mobile markets. Utilization of different devices, especially smartphones and tablets has considerably improved fields like communications, medicine, commerce, media and entertainment. Their emergence has improved service delivery, empowered consumers, businesses and entrepreneurs and has changed the way in which people access information and makes transactions. [1] Now, this technology is used to alter how healthcare services are delivered, the quality of the patient experience and furthermore, the cost of healthcare. Mobile technology is helping patients with their chronic disease management, extending service to rural areas and more than that, it is improving health outcomes and the growth of medical system efficiency.

Mobile phones as a service platform can provide several societal, medical, educational, business and governmental services. Further developments will also allow mobile devices with unique features that can sense the environment and physiological parameters to enhance quality of life and remote monitoring of patients. [2] On the other side, mobile devices are being characterized by having limitations in what concerns their computational capacity and also, power and resource consumption. Based on this assumption, mobile cloud computing could be considered a solution and more than that, an unlimited resource that can be accessed anytime and anywhere all over the world, by anyone.

The healthcare industry is in a period of accelerating change that requires continual innovation. The chronic disease epidemic, changing population demographics and advancements in medical technologies are key contributors to escalating costs. [3] The need of change is continuously growing and requesting a more complex and higher quality of medical care services delivered to patients. Hospitals management and also physicians need to adopt 
new strategies in order to increase the flexibility of medical care providers and in the same time to demonstrate an increase in what concerns healthcare provided value. In order to reach this target, a transformation from institution-centered, data-poor systems to patientcentered, information-rich health systems is definitely needed.

\section{Theoretical frameworks}

Cloud computing offers new and flexible ways to provision, manage and pay for technology resources. [3] It is allowing new and more efficient business models which can be used within many domains including medicine, education or commerce. Cloud computing is a general term for anything that involves the delivery of technology over the Internet. It is a model for enabling convenient, on-demand network access to a shared pool of configurable computing resources (for example, networks, systems, applications and services) that can be rapidly provisioned and released with minimal management effort or service provider interaction. [4] This concept is characterized by the following concepts [5]:

- On-demand self-service

On-demand self-service makes IT resource capacity within a cloud infrastructure appear infinite to users. A consumer can unilaterally provision computing capabilities, such as server time and network storage, as needed automatically without requiring human interaction with each service's provider. This is also a critical aspect of a complete cloud environment due to the fact that inefficient business logics, a continuous and unlimited demand for a private cloud within different organizations can quickly lead to an exceed in what concerns cloud it's capacity allocation and supply.

- Ever-present network access to computing resources

Cloud capabilities are available over the network and accessed through standard mechanisms that promote use by heterogeneous thin or thick client platforms such as mobile phones, laptops and PDAs. The provider's computing resources are pooled together to serve multiple consumers using multiple-tenant model, with different physical and virtual resources dynamically assigned and reassigned according to consumer demand. The resources include among others storage, processing, memory, network bandwidth, virtual machines and email services. The pooling together of the resource builds economies of scale.

- Rapid and elastic provisioning with minimal management effort or service provider interaction

Cloud services can be rapidly and elastically provisioned, in some cases automatically, to quickly scale out and rapidly released to quickly scale in. To the consumer, the capabilities available for provisioning often appear to be unlimited and can be purchased in any quantity at any time.

- Pay-per-use

Cloud computing resource usage can be measured, controlled, and reported providing transparency for both the provider and consumer of the utilized service. Cloud computing services use a metering capability which enables to control and optimize resource use. This implies that just like air time, electricity or municipality water IT services are charged per usage metrics - pay per use. Just as utility companies sell power to subscribers and telephone companies sell voice and data services, IT services such as network security management, data center hosting or even departmental billing can now be easily delivered as a contractual service.

One of the overall goals of adopting cloud computing solutions consist in administrating complexity more effectively and this can be achieved by simplifying processes in order to speed up the developing of other new capabilities that can ensure innovation in many fields. Despite the fact that cloud computing has been associated with infrastructure, the ability to generate new values in terms of process innovation and significant cost savings is one of its main advantages and focus.

Cloud computing provides a platform for 
business-to-business and business-to-consumer collaboration and enables organizations to focus on differentiating activities as distinct from transactional processes. There are four basic models of cloud services which are illustrated in Figure 1 as follows [6]:

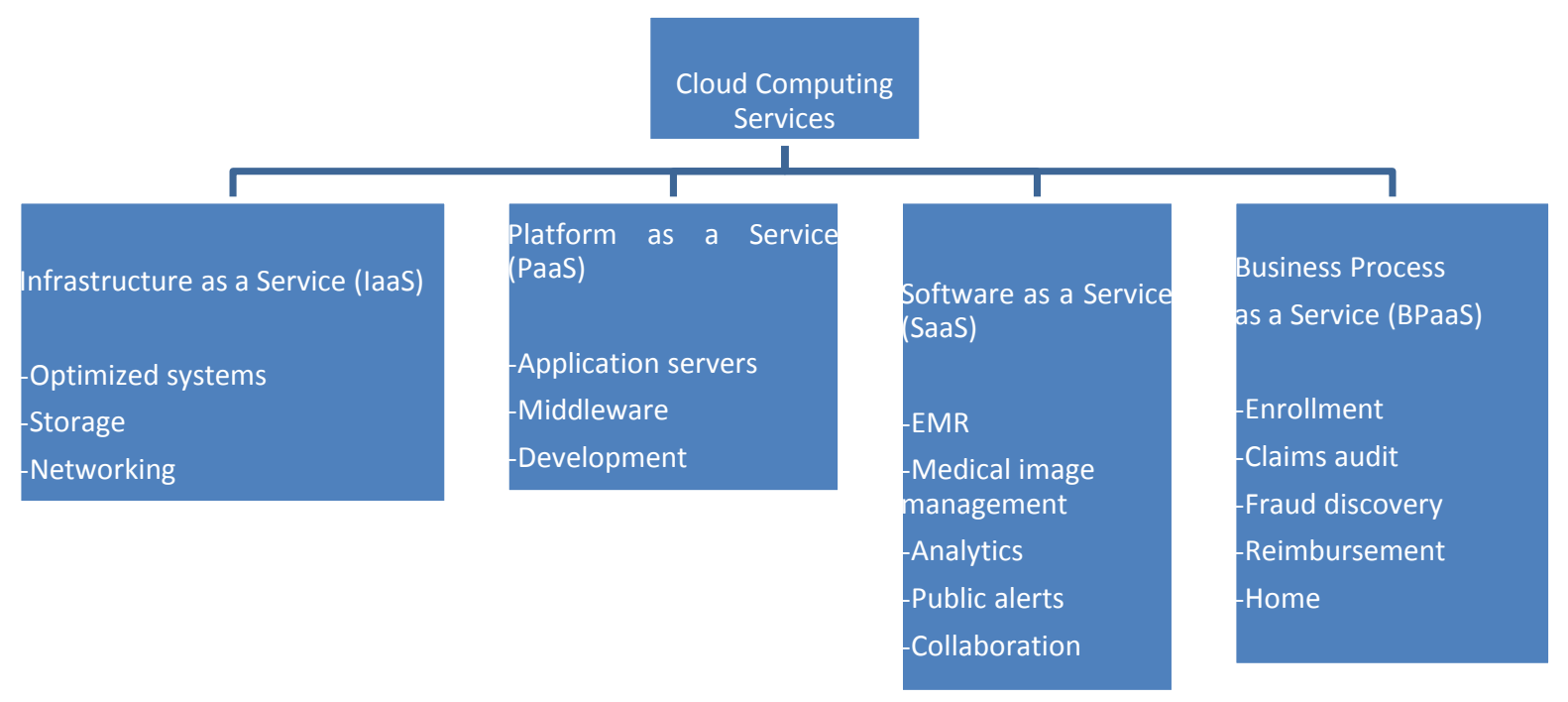

Fig.1. Cloud Computing Services

- Infrastructure as a Service (IaaS)

The advantage provided to the consumer consists in provision processing, storage, networks, and other fundamental computing resources where the consumer is able to deploy and run arbitrary software, which can include operating systems and applications. The consumer does not manage or control the underlying cloud infrastructure but is gaining control over operating systems, storage and deployed applications and furthermore over the possibly limited control of select networking components (e.g., host firewalls).

- Platform as a Service (PaaS)

The main capability provided to the consumer is to deploy onto the cloud infrastructure consumer-created or acquired applications created using programming languages, libraries, services and tools supported by the provider. The consumer does not manage or control the underlying cloud infrastructure including network, servers, operating systems, or storage, but has control over the deployed applications and possibly configuration settings for the application-hosting environment.
- Software as a Service (SaaS)

The capability provided to the consumer is to use the provider's applications running on a cloud infrastructure. The applications are accessible from various client devices through either a thin client interface, such as a web browser (e.g., web-based email), or a program interface.

In this case, the consumer does not manage or control the underlying cloud infrastructure including network, servers, operating systems, storage, or even individual application capabilities, with the possible exception of limited user-specific application configuration settings.

- Business Process as a Service (BPaaS)

This represents the delivery of business process outsourcing services that are sourced from the cloud and constructed for multitenancy. Services are often automated and where human process actors are required, there is no overtly dedicated labor pool per client. The pricing models are consumption-based or subscription-based commercial terms. As a cloud service, the BPaaS model is accessed via Internetbased technologies. [7] 
The concept of "Mobile Cloud Computing" was introduced soon after the concept of "Cloud Computing" one which was launched in mid 2007. It was defined in a 5 March 2010 entry in the Open Gardens blog as "the availability of cloud computing services in a mobile ecosystem. This incorporates many elements, including consumer, enterprise, femtocells, transcoding, end-to-end security, home gateways and mobile broadband-enabled services." (A femtocell is a small cellular base station.) [8]

Since then, it has been considered a profitable business option which helps in the process of reducing the development and costs needed to deploy mobile applications. Moreover, in what concerns mobile users, this is considered as a new technology needed to achieve rich experience of a variety of mobile services at low cost.

The growth of the mobile computing market is being enhanced by a wide range of enabling technologies including 4G, HTML5, CSS3, cloudlets, Web 4.0, hypervisor etc. The impact of the broad introduction of tablet computers in 2011 could be an added motivator for advancements, as well.

According to „Cisco's Visual Networking Index Global Mobile Data Traffic Forecast Update" [9], consumers' mobile utilization of mobile devices and services has grown significantly in the past years and it shows no signs of slowing. In fact, Cisco predicts global mobile data traffic will increase by 13 percent by
2018, with more than 10 billion mobile-connected devices by then. It also believes mobile network speeds will grow by seven times what it is now. Some of the statistics mentioned in that study [9] are presented in this paper in order to enhance and demonstrate the continuous increase of mobile market which has a positive impact on the continuous development of mobile cloud computing technologies.

The continuous increase of the number of wireless devices which are accessing mobile networks all around the world is one of the main factors that contribute to global mobile traffic growth. Several new devices are introduced every year on the market in different form factors and with new or improved capabilities, facilities and.

Based on the mentioned study, more than a half a billion (526 million) of mobile devices and connections were added last year, in 2013, on the mobile market. Global mobile devices and connections grew, in 2013, to 7 billion, up from 6.5 billion which were estimated in 2012. As shown in Figure 3, globally, mobile devices and connections will grow to 10.2 billion by 2018 at a CAGR of 8 percent.

More than that, by the end of 2018 , there will be 8.2 billion (Figure 2) handheld or personal mobile-ready devices and 2 billion machineto-machine connections (e.g., GPS systems in cars, asset tracking systems in shipping and manufacturing sectors or medical applications making patient records and health status more readily available).

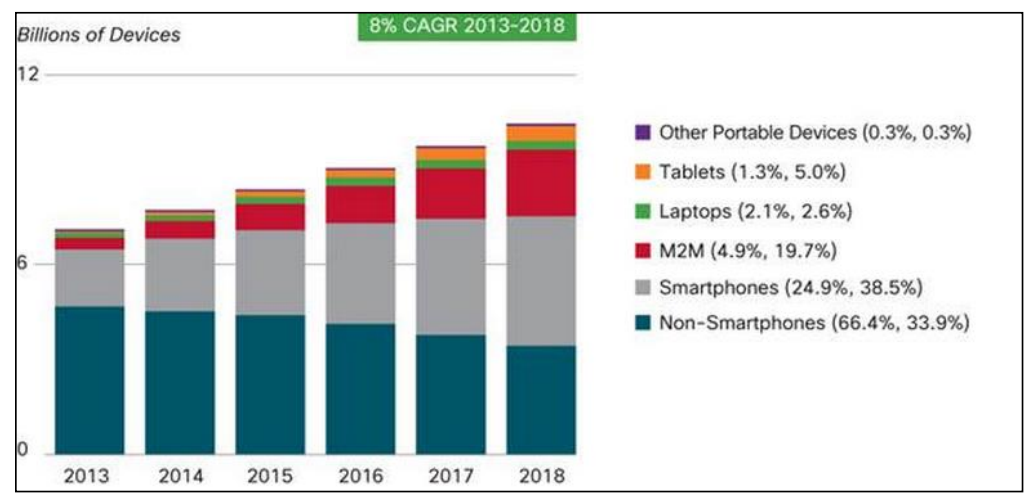

Fig.2. Device or connection share expected in 2018

As shown in the above figure, there is a decline in what concerns the usage of non- smartphones mobile devices from more than 66 percent in 2013 ( 4.7 billion) to less than 34 
percent by 2018 (3.5 billion). Based on the same graphic, it seems that a noticeable growth is going to occur in tablets devices, followed by machine-to-machine connections (M2M). The first ones are going to grow at 41 percent CAGR from 2013 to 2018 and the M2M category is going to grow at 43 percent CAGR during the period taken into consideration for the estimation model of their study. Globally, the relative share of $3 \mathrm{G}$ and $3.5 \mathrm{G}$ capable devices and connections will surpass 2G-capable devices and connections by 2016 (48 percent and 44 percent relative share). By 2018,15 percent of all global devices and con- nections will be $4 \mathrm{G}$ capable as shown in Figure 3. The global mobile $4 \mathrm{G}$ connections will grow from 203 million in 2013 to 1.5 billion by 2018 at a CAGR of 50 percent.

The growth in $4 \mathrm{G}$, with its main characteristics based on a higher bandwidth, a lower latency and furthermore, a more increased security facility, will have a major impact in the processes of overcoming the gaps which exists between their mobile and their fixed network performance. This will lead to even higher adoption of mobile technologies by end users, making access to any content on any device from anywhere more of a reality.

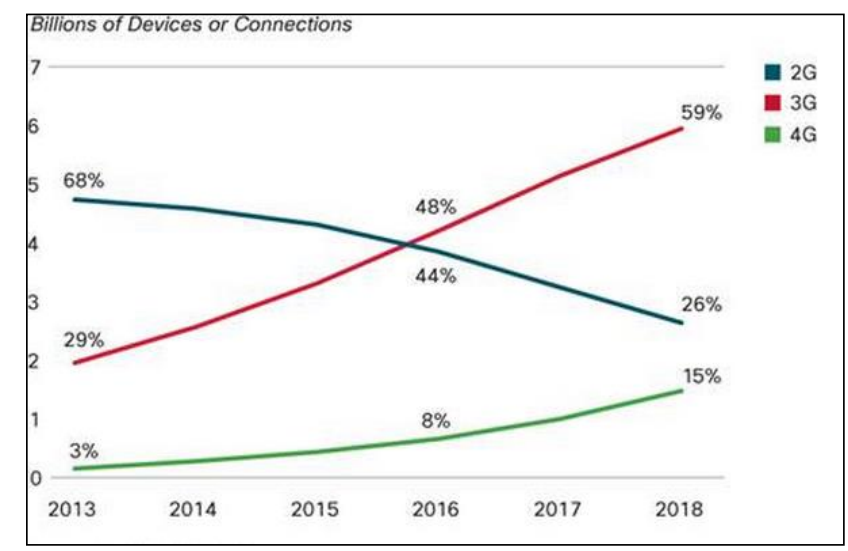

Fig.3. Device or connection share expected based on 4G comparison in 2018

In what concerns a $4 \mathrm{G}$ connection, this currently generates almost 15 times more traffic than a non- $4 \mathrm{G}$ connection. This capability is based on some technical advantages including the following two aspects:

- The 4G connections-based mobile devices are for high-end devices, which are being characterized by a higher average usage.

- A higher speed which contributes in the process of adopting and usage of highbandwidth applications. Therefore, a smartphone with a $4 \mathrm{G}$ network is likely to generate 50 percent more traffic than the same model smartphone on a $3 \mathrm{G}$ or $3.5 \mathrm{G}$ network.

As smartphones come to represent a larger share of $4 \mathrm{G}$ connections, the gap between the average traffic of $4 \mathrm{G}$ devices and non- $4 \mathrm{G}$ devices will narrow, but by 2018 a 4G connection will still generate 6 times more traffic than a non- $4 \mathrm{G}$ connection, according to the same study.
The phenomenal growth in smarter end-user devices and M2M connections is a clear indicator of the growth of the Internet of everything which is bringing together people, processes, data and things to make networked connections more relevant and valuable. As real-time information monitoring helps companies deploy new video-based security systems, while also helping hospitals and healthcare professionals remotely monitor the progress of their patients, bandwidth-intensive $\mathrm{M} 2 \mathrm{M}$ connections are becoming more prevalent. [9]

Globally, M2M connections will grow from 341 million in 2013 to over 2 billion by 2018, a 43 percent CAGR. M2Mcapabilities similar to end-user mobile devices are migrating from $2 \mathrm{G}$ to $3 \mathrm{G}$ and $4 \mathrm{G}$ technologies. In 2013, 71 percent of global mobile M2M connections were connected using $2 \mathrm{G}$ connectivity, while 28 percent used $3 \mathrm{G}$, and less than 0.5 percent used 4G. By 2018, only 35 percent of M2M 
modules will have a connectivity of $2 \mathrm{G}, 51$ percent will have $3 \mathrm{G}$ connectivity and 14 percent will have $4 \mathrm{G}$ connectivity. While $3 \mathrm{G}$ and $3.5 \mathrm{G}$ account for the majority (60 percent) of mobile data traffic today, $4 \mathrm{G}$ will grow to represent over half of all mobile data traffic by 2018 , despite a connection share of only 15 percent as shown in Figure 4 from below.

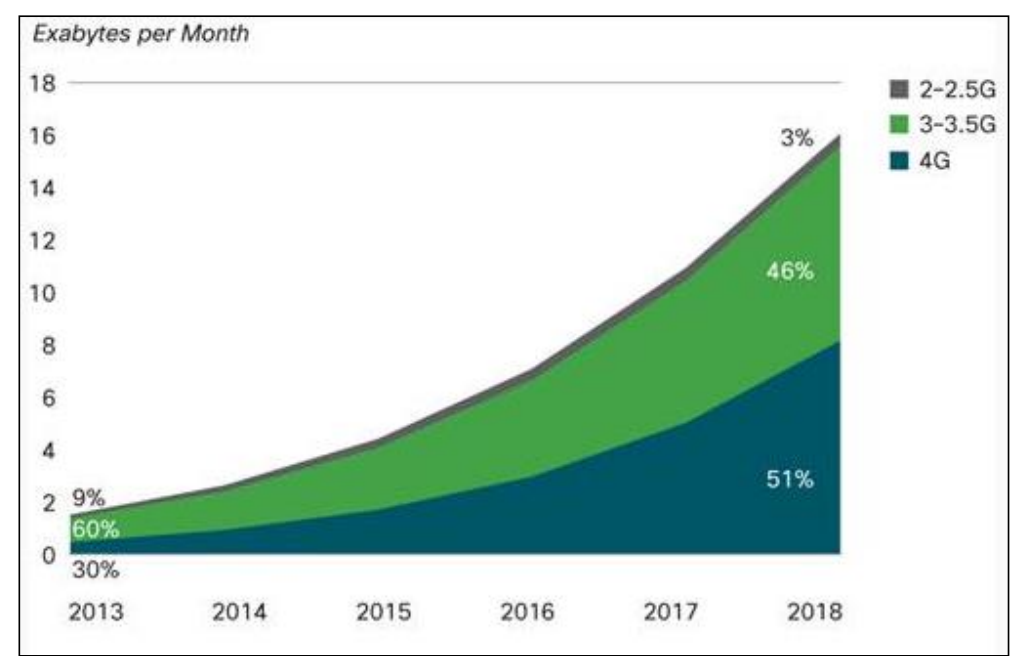

Fig.4. Mobile device connectivity evolution expected by 2018

One of the primary advantage of mobile cloud computing is derived from the cloud computing capabilities and therefore, as an inheritance and development from this, it consists in the virtualization of resources and their assignation in a group of numerous distributed computers and not in traditional local computers or servers. This is being specific, especially to mobile devices such as smartphones, portable terminal, and so on. Meanwhile, various applications based on mobile cloud computing have been developed and provided to end-users, such as Google's Gmail, Maps and
Navigation systems for Mobile, Voice Search, and some applications on an Android platform, Mobile Me from Apple, Live Mesh from Microsoft, and Moto Blur from Motorola. [10] According to the research from Cisco, which was presented above, the cloud computing based mobile software and application are expected to rise annually from 2013 to 2018 and more similar application to the ones listed above to be shared to end-mobile users.

A conceptual general architecture of mobile cloud computing is presented in Figure 5.

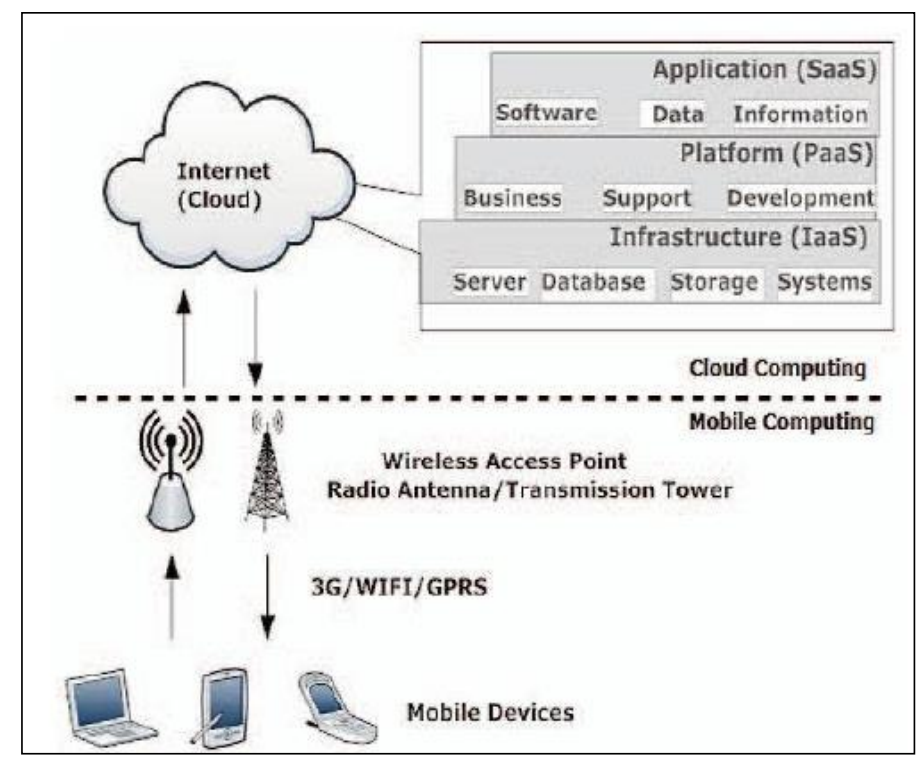


Fig.5. Mobile cloud Computing architecture [11]

Based on the above architecture, Mobile Cloud Computing technology can be simply divided into the two general technologies based on which it was developed:

- Mobile computing

Mobile devices can be represented by smartphones, laptops or PDAs, which can be connected to a network through $3 \mathrm{G}$, WIFI or GPRS technologies. Cloud requests can be sent by mobile end-users through different mobile web browsers and resources will be allocated to the connections which were established.

After the moment in which the web application is being initialized and started, some system functions including monitoring and calculating, will be deployed in order to ensure that the quality of service will be maintained until the moment in which the connection will be completed.
During this process, some tasks are being accomplished and these includes operation like providing response rapidly, synchronizing and load balancing, all of them having the main objective of guaranteeing that the resources are allocated efficiently to the most appropriate clients.

- Cloud computing

Integrating cloud computing with mobile devices, some of the most important constraints applied to mobile computing are being overcome and the noticeable ones include battery life and hardware with less computational power. There are being resolved by moving the most complex operations and computations in the cloud.

Some of the main advantages offered by mobile cloud computing technology are illustrated in Table 1 as follows [12]:

Table 1. Mobile Cloud Computing Advantages

\begin{tabular}{|c|l|}
\hline MCC Advantage & \multicolumn{1}{c|}{ Description } \\
\hline \multirow{2}{*}{$\begin{array}{l}\text { Extend mobile battery } \\
\text { lifetime }\end{array}$} & $\begin{array}{l}\text { Battery is one of the main concerns for mobile devices. Sev- } \\
\text { eral solutions have been proposed to enhance the CPU perfor- } \\
\text { mance and to manage the disk and screen in an intelligent } \\
\text { manner to reduce power consumption. However, these solu- } \\
\text { tions require changes in the structure of mobile devices, or } \\
\text { they require a new hardware that results in an increase of cost } \\
\text { and may not be feasible for all mobile devices. }\end{array}$ \\
\begin{tabular}{|c|l|} 
Computation offloading techniques are migrating large com- \\
putations and complex processing from resource-limited de- \\
vices (i.e., mobile devices) to more resourceful machines (i.e., \\
servers in clouds). This avoids taking a long application exe- \\
cution time on mobile devices which results in large amount \\
of power consumption evaluate the effectiveness of offloading \\
techniques through several experiments. Therefore, this lead \\
to the fact that remote application execution can save energy \\
significantly. \\
Many mobile applications take advantages from task migra- \\
tion and remote processing.
\end{tabular} \\
\hline $\begin{array}{l}\text { MCC enables mobile users to store and access large data on } \\
\text { and processing power } \\
\text { the cloud. } \\
\text { MCC helps reduce the running cost for computation inten- } \\
\text { sive applications. } \\
\text { Mobile applications are not constrained by storage capacity } \\
\text { on the devices because their data now is stored on the cloud. }\end{array}$ \\
\hline
\end{tabular}




\begin{tabular}{|c|c|}
\hline $\begin{array}{l}\text { Reliability and availa- } \\
\text { bility }\end{array}$ & $\begin{array}{l}\text { - Keeping data and application in the clouds reduces the } \\
\text { chance of lost on the mobile devices. } \\
\text { - MCC can be designed as a comprehensive data security } \\
\text { model for both service providers and users: } \\
\text { - Protect copyrighted digital contents in clouds. } \\
\text { - Provide security services such as virus scanning, malicious } \\
\text { code detection and authentication for mobile users. } \\
\text { - With data and services in the clouds, then are always availa- } \\
\text { ble even when the users are moving. }\end{array}$ \\
\hline Dynamic provisioning & $\begin{array}{l}\text { Dynamic on-demand provisioning of resources on a fine- } \\
\text { grained, self-service basis } \\
\text { - No need for advanced reservation }\end{array}$ \\
\hline Scalability & $\begin{array}{l}\text { - Mobile applications can be performed and scaled to meet the } \\
\text { unpredictable user demands } \\
\text { - Service providers can easily add and expand a service }\end{array}$ \\
\hline Multi-tenancy & $\begin{array}{l}\text { Service providers can share the resources and costs to sup- } \\
\text { port a variety of applications and large number of users }\end{array}$ \\
\hline Ease of Integration & $\begin{array}{l}\text { Multiple services from different providers can be integrated } \\
\text { easily through the cloud and the Internet to meet the users' } \\
\text { demands }\end{array}$ \\
\hline
\end{tabular}

Cloud is an extremely powerful resource which allows users to perform complex computations while computing ability of mobile devices has a very limited and based on many issues opportunity of achieving the same. Some restrictions in what concerns implementing Mobile Cloud Computing into mobile devices exists and are represented by the limited resources of those devices, they could be related to network performance or to security of mobile users and clouds. Other major constraints in what concerns the process of implementing mobile cloud computing architectures are based on limited energy and wireless bandwidth. From this point of view e.g. power consumption, cloud computing technologies can be divided into two main categories: cloud and non-cloud solutions. [13]

Cloud based applications consume more power than the non-cloud does. This is because of the Wi-Fi interface on mobile devices which is being an important factor in what concerns power consumption but wireless performance is continuously increasing in terms of efficiency and the situation is improving constantly.

Other restrictions related to mobile cloud computing are represented by the hardware limits which are being characterized by a less computational capacity and availability. This limitation can also be improved by migrating complex operations to dedicated computers from the cloud. Also, based on the continuous development and expansion of $4 \mathrm{G}$ connectivity technology, the availability issue can be improved considerably.

Another issue lies on the problems related to security and privacy and in order to overcome these barriers, the threat detection services are performed in clouds and still some security issues like device security, privacy of mobile user and securing data on cloud remains as there are so many security threats like viruses, hacking, Trojan horses in mobile devices also.

\section{Telemedicine applications}

Cloud computing and mobile cloud computing represent the new IT approaches that offer new economic benefits, an efficient process of service deployment and tight technological alignment with medicine goals. Due to the potential of cloud computing, the healthcare industry can take advantage of this technology in order to develop telemedicine solution which will help in the process of improving the quality and efficiency of medical 
services.

Mobile Cloud Computing offers important advantages to the healthcare sector, especially in what concerns virtual clinics, hospitals and healthcare clinics which all require an almost immediate access to computing facilities but also to large storage options which are not often ensured by the traditional medical environments. Moreover, healthcare information are needed across various settings and geographies locations in order to overcome this kind of limits and to avoid some significant delays during patients treatment or loss of time for both sides, medics and patients. This new technological approach provides an opportunity to improve medical services, to share information more easily between healthcare providers (physicians, researchers, pharmacists etc) and also to improve operational efficiency in the same time. In the following table, I have listed some of the main benefits which cloud and mobile cloud provide to different services specific to telemedicine systems. [14]

Table 2. Telemedicine opportunities based on cloud computing advantages

\begin{tabular}{|c|c|}
\hline Telemedicine service & Cloud solution \\
\hline Clinical research & $\begin{array}{l}\text { Many pharmacology vendors are starting to integrate the } \\
\text { cloud in order to improve research and drug development. } \\
\text { Currently, pharmacology firms do not have the capacity to } \\
\text { run large datasets, especially DNA sequencing - as the size } \\
\text { of the data can overwhelm their computers. Commercial } \\
\text { cloud vendors have developed pharmacology specific } \\
\text { clinical research cloud offerings with the goal of lowering } \\
\text { the cost and development of new drugs. }\end{array}$ \\
\hline $\begin{array}{l}\text { Electronic Medical } \\
\text { Records }\end{array}$ & $\begin{array}{l}\text { Hospitals and physicians are starting to see cloud-based } \\
\text { medical records and medical image archiving services } \\
\text { coming on line. The objective is to offload a burdensome } \\
\text { task from hospital IT departments and allow them to focus } \\
\text { on supporting other imperatives such as EMR adoption } \\
\text { and improved clinical support systems. }\end{array}$ \\
\hline $\begin{array}{l}\text { Collaboration solu- } \\
\text { tions }\end{array}$ & $\begin{array}{l}\text { Early successes of cloud-based physician collaboration } \\
\text { solutions such as remote video conference physician visits } \\
\text { are being trialed. Extending such offerings to a mobile en- } \\
\text { vironment for rural telehealth or disaster response is be- } \\
\text { coming more real with broader wireless broadband and } \\
\text { smartphone adoption. Cloud technology supports collabo- } \\
\text { ration and team-based care delivery and the ability to use } \\
\text { applications based on business model requirements and a } \\
\text { common set of clinical information. }\end{array}$ \\
\hline Real-time monitoring & $\begin{array}{l}\text { With the increase in availability of mobile technologies } \\
\text { and intelligent medical devices, telemedicine has grown to } \\
\text { include not only tele-consultations and telesurgeries, but } \\
\text { also health record exchange, video-conferencing, and } \\
\text { home monitoring. }\end{array}$ \\
\hline $\begin{array}{c}\text { Health Information } \\
\text { Exchange }\end{array}$ & $\begin{array}{l}\text { Health information exchanges help healthcare organiza- } \\
\text { tions to share data contained in largely proprietary EHR } \\
\text { systems. }\end{array}$ \\
\hline $\begin{array}{l}\text { Image viewing sup- } \\
\text { port }\end{array}$ & $\begin{array}{l}\text { The DICOM protocol is supported for medical imagine, } \\
\text { while the JPEG } 2000 \text { standard has been }\end{array}$ \\
\hline
\end{tabular}




\begin{tabular}{|l|l|}
\hline & implemented in order to support loss and lossless com- \\
pression, progressing coding and Region of Interest (ROI) \\
coding. The progressive coding allows the user to decode \\
large image \\
files at different resolution levels optimizing this way net- \\
work resources and allowing image acquisition even in \\
cases network availability is limited. The code for per- \\
forming wavelet decoding on mobile devices in [15] has \\
been modified to support the JPEG2000 standard on the \\
Android platform. Image annotation is also supported, us- \\
ing the multi-touch functions of the Android OS.
\end{tabular}

The healthcare industry confronts with a multitude of issues, including the following:

- Strong need for medical-related cost reduction;

- Strong need for operating efficiencies and increased productivity in what concerns medical services which are needed to be provided by healthcare physicians;

- Need to automate care delivery processes and systems;

- Need to modernize legacy applications and systems;

- Comply with regulations and security mandates;

- Use data to analyze and improve clinical and business performance;

- Expand access to medical care services especially in rural areas;

- Demonstrate greater healthcare value to all patients;

- Need for business model innovation in order to improve medical institutions sustainability.

Mobile cloud computing has a major contribution in the process of transforming healthcare system and improving all the issues listed above and related to the medical field. This supports collaboration, team-based healthcare delivery and also the ability to use medical applications which are based on different requirements and on some clinical sets of information.

It provides access to a platform which allows healthcare institutions to deliver, use and furthermore, to integrate new medical services based on a comprehensive and longitudinal view of patients records. This provides some benefits including:

- maintains a level of security and privacy all around the cloud, for all medical-care services related;

- reduces IT costs based on the implemented cloud infrastructure;

- speeds service and infrastructure availability;

- reduces capital expenditures and the need to replicate hardware environments for each platform change which is being done or for each medical service which is being added;

- increases the possibility of adding capacity rapidly when it is needed based on business requirements.

Mobile cloud computing integrated in telemedicine field focus towards achieving two specific goals: the availability of health applications and medical information anywhere and anytime and the invisibility of computing. [16] Mobile pervasive healthcare technologies can support a wide range of applications and services including mobile telemedicine, patient monitoring, location-based medical services, emergency response and management, personalized monitoring and pervasive access to healthcare information, providing great benefits to both patients and medical personnel. [15]

Based on the characteristics of Mobile Cloud Computing and the flexibility of the services that can be developed within this environment, an important benefit consists in the agility that improves with users being able to rapidly and inexpensively re-provision technological infrastructure resources. Hence, this lead to the possibility of users being able to 
access medical systems by using a web browser, regardless of their location or on the category of mobile device which is being used (e.g., mobile phones, smartphone, tablets etc). The integration of advanced cloud technologies within the medical field will bring new values in what concerns the option of sharing medical information and data stored in large databases and the possibility of being able to integrate mechanism for aggregating, mining, and analyzing those large amounts of data represented by medical processes, treatments, drugs, diseases, effectiveness, costs and medical conditions. Cloud environments which integrate big data solutions can be shared to healthcare providers in order for them to have access to important information which can be used during medical interventions in order to avoid medical errors.

Mobile cloud computing integrated with telemedicine solutions (m-telemedicine) allows patients to be monitored at any time, any place through wireless technology. Mobile computing devices create more free space, less clutter and lower costs, while delivering more services more efficiently [17]. Applying mobile cloud computing in medical applications could minimize the limitations of traditional medical treatment (e.g., small physical storage, security and privacy, and medical errors. This provides mobile users with convenient helps to access resources (e.g., patient health records) in a more rapid and easy manner. In addition, this technology offers hospitals and healthcare providers a variety of on-demand services on clouds. It presents the following mobile healthcare applications in the pervasive environment [18]:

- Comprehensive health monitoring services which allow patients to be monitored at anytime and anywhere through broadband wireless communications;

- Intelligent emergency management system that can be used to manage and coordinate the fleet of emergency vehicles effectively and in time when receiving calls from accidents or incidents;

- Health-aware mobile devices which can be used to detect pulse-rate, blood pressure, and level of alcohol to alert healthcare emergency system;

- Pervasive access to healthcare information which allows patients or healthcare providers to access the current and past medical information.

\section{Conclusions}

Mobile Cloud Computing integrates cloud computing into the mobile environment and overcomes mobile devices' limitations in what concerns the performance, medical environment, and data security. MCC solutions for telemedicine have a major contribution in the process of minimizing the limitations of traditional medical treatment including medical errors, small physical storage and security and privacy issues. These limitations and challenges are overcome by incorporating advanced technologies like $4 \mathrm{G}$ connectivity and can be used to improve patient outcomes through quality services in what concerns measurement and monitoring, evaluation, assessment, diagnosis processes and also, interventions, treatments, rehabilitation, workflow and collaboration within healthcare providers and consumers.

\section{Acknowledgment}

This paper received financial support through the "Route of academic excellence in doctoral and postdoctoral research - READ", Contract no. POSDRU/159/1.5/S/137926, project cofinanced by the European Social Fund for the Sectorial Operational Program for Human Resources Development 2007-2013.

\section{References}

[1] D. West, "How Mobile Devices are Transforming Healthcare", 2012, Available: http://www.insidepolitics.org/brookingsreports/mobile_health_52212.pdf

[2] R. Baniwal, "Applications of Cloud Computing in Different Areas", 2013, Available: http://www.csjournals.com/IJCSC/PDF4-2/5c.pdf

[3] "Cloud Computing: Building a New Foundation for Healthcare", Available: https://www05.ibm.com/de/healthcare/literature/cloud-new-foundation-for-hv.pdf 
[4] "Introduction to Cloud Computing", Available: https://www.priv.gc.ca/resource/fs-fi/02_05_d_51_cc_e.pdf

[5] P. Mell and T.Grance, "The NIST Definition of Cloud Computing", Available: http://csrc.nist.gov/publications/nistpubs/800-145/SP800-145.pdf

[6]"Cloud Computing Definition", Available: http://www.service-architecture.com /articles/cloud-computing/cloud__ computing_definition.html

[7]" Business Process as a Service (BPaaS)", Available: http://www.gartner.com/itglossary/business-process-as-a-servicebpaas

[8] "Mobile cloud computing: Devices, trends, issues, and the enabling technologies", Available: http://www.ibm.com/developerworks/cloud/library/cl-mobilecloudcomputing/

[9] "Cisco VNI Global Mobile Data Forecast Update (2013 - 2018)", Available: http://blogs.cisco.com/news/cisco-vniglobal-mobile-data-forecast-update-20132018/

[10] "Mobile Cloud Computing", Available: http://www.academia.edu/5336746/MOBILE_CLOUD_COMPUTING

[11] Q. Haan and A. Gani, "Research on Mobile Cloud Computing: Review, Trend and Perspectives", Available: http://arxiv.org/pdf/1206.1118.pdf

[12] T. Dinh, C. Lee, D. Niyato and P.Wang, "A Survey of Mobile Cloud Computing:
Architecture, Applications, and Approaches", Available: http://www.eecis.udel.edu/ cshen/859/pa pers/survey_MCC.pdf

[13] E. Almrot, "A study of the advantages \& disadvantages of mobile cloud computing versus native environment", Available: http://www.bth.se/fou/cuppsats.nsf/all/09 e29677bfc8ef2ec1257baa0030b399/\$file/ BTH2013Almrot.pdf

[14] "Impact of Cloud Computing on Healthcare" Available: http://www.cloudstandardscustomercouncil.org/cscchealthcare110512.pdf

[15] I. Maglogiannis, C. Doukas, G. Kormentzas and T. Pliakas, "Wavelet-Based Compression With ROI Coding Support for Mobile Access to DICOM Images Over Heterogeneous Radio Networks", IEEE Transactions on Information Technology in Biomedicine, vol.13, no.4, pp.458-466, July 2009

[16] U. Varshney, "Pervasive Healthcare", IEEE Computer Magazine vol. 36, no. 12, 2003, pp. 138-140

[17] P. Asrani, "Mobile Cloud Computing", International Journal of Engineering and Advanced Technology (IJEAT), vol.2, no.4, April 2013, pp. 606-609

[18] H. T. Dinh, C. Lee, D. Niyato, and P. Wang, "A Survey of Mobile Cloud Computing: Architecture, Applications, and Approaches", Wireless Communications and Mobile Computing - Wiley

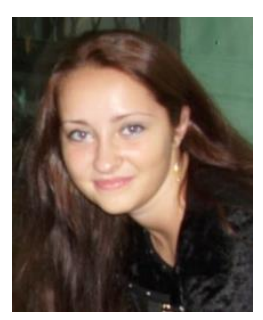

Mihaela GHEORGHE has graduated the Faculty of Economic Cybernetics, Statistics and Informatics of the Bucharest University of Economic Studies in 2010 as a promotion leader. In 2012 she graduated the Informatics Economics Master program also as a promotion leader. She is currently conducting research in Economic Informatics at Bucharest University of Economic Studies, coordinated by Professor dr. Bogdan Ghilic-Micu for her PhD thesis "Architecture and technologies in telemedicine". She was a pre-Assistant within the Department of Economic Informatics between 2012 and 2013. Currently she is working as a software engineer at IBM Corporation, since 2012. Her main scientific interests include: telemedicine system, mobile technologies. 